\title{
Charles Nodier et le roman gothique, dir. Ė. Pézard
}

\section{Michel Arrous}

\section{(2) OpenEdition}

\section{Journals}

\section{Édition électronique}

URL : https://journals.openedition.org/studifrancesi/21356

DOI : 10.4000/studifrancesi.21356

ISSN : 2427-5856

\section{Éditeur}

Rosenberg \& Sellier

\section{Édition imprimée}

Date de publication : 1 décembre 2019

Pagination : $581-582$

ISSN : 0039-2944

\section{Référence électronique}

Michel Arrous, "Charles Nodier et le roman gothique, dir. Ė. Pézard », Studi Francesi [En ligne], 189 (LXIII I III) | 2019, mis en ligne le 01 mars 2020, consulté le 11 novembre 2021. URL : http://

journals.openedition.org/studifrancesi/21356 ; DOI : https://doi.org/10.4000/studifrancesi.21356

Ce document a été généré automatiquement le 11 novembre 2021.

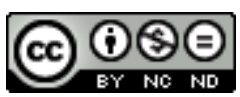

Studi Francesi è distribuita con Licenza Creative Commons Attribuzione - Non commerciale - Non opere derivate 4.0 Internazionale. 


\title{
Charles Nodier et le roman gothique, dir. Ė. Pézard
}

\author{
Michel Arrous
}

\section{RÉFÉRENCE}

Charles Nodier et le roman gothique, dir. Ė. Pézard, "Cahiers d'études nodiéristes" 6, 2018-2, Paris, Classiques Garnier, 2018, 212 pp.

1 Éminente spécialiste du romantisme «frénétique», Émilie Pézard a assuré la direction de ce numéro aussi riche que le précédent et qui s'ajoute heureusement au colloque Autour de "Jean Sbogar" de Charles Nodier. Le bicentenaire d'un roman majeur du romantisme (Paris, juin 2018). Les sept contributeurs au dossier «Charles Nodier et le roman gothique» (pp.19-162) examinent, non sans quelques répétitions, l'appropriation par Nodier des codes du genre gothique, ainsi que son rôle parfois ambigu dans la réception dudit genre dans les années 1820 .

2 Séduit par la veine noire dont relève le roman gothique, et réticent devant la dégradation du goût qu'elle implique, Nodier délaissera les «radcliffades» et assurera la promotion du fantastique à l'aube des années 1830. L'engouement pour le roman gothique tient sans nul doute à des traits spécifiques (persécution, inceste, meurtre, vengeance) dans des cadres types (château, souterrain, corridor, cachot, ruine), autant d'indices formant un système qu'en 1997 Maurice Lévy a résumé par une heureuse formule: «le gothique, c'est l'héroïne et le labyrinthe». Dans l'espace gothique, il y a un motif conventionnel que Nodier, pourtant soucieux d'originalité, à intégré à son univers romanesque: ce que Joëlle Prungnaud a nommé la «demeure noire» où sévit un personnage terrifiant.

3 À partir des exemples du château de Duino dans Jean Sbogar et de la Torre Maladetta dans le dernier épisode de Mademoiselle de Marsan, Tomonao Fujita démontre parfaitement la «complicité de Nodier avec la veine gothique». Mais plus qu'au plaisir factice de la terreur, le romancier fait de cet espace emblématique «le lieu du 
dévoilement des conflits intérieurs» (Le château gothique chez Nodier. Réflexions autour d'un motif, pp. 19-34). L'attitude ambivalente de Nodier devant le roman gothique est perceptible dans le traitement qu'il réserve aux aspects fondamentaux de l'esthétique élaborée par Radcliffe et Lewis.

Dans son article "Jean Sbogar", un roman gothique? (pp. 35-53), Nicolas Leblanc montre que Nodier procède à la fois par emprunts et mise à distance des traits et des artifices propres aux deux romanciers anglais. Cet infléchissement ou plutôt ce détournement du roman noir, par exemple dans le traitement de la dynamique de persécution (voir le personnage à la fois scélérat et sauveur, Jean Sbogar / Lothario) et une «esthétique du choc», prouvent évidemment que Nodier se nourrit de l'esthétique gothique, mais aussi qu'il s'en distingue en privilégiant les caractéristiques du roman frénétique romantique.

5 La situation de Nodier par rapport à Ann Radcliffe, Clara Reeve (auteur de The old English Baron, 1778, inspiré par The Castle of Otranto de Walpole, et de The Progress of romance through times, countries and manners, 1785), Mary Shelley, Charles Maturin et Matthew Gregory Lewis, Fiona McIntosh-Varjabédian l'évoque indirectement avec Réception et légitimité du roman gothique en Grande-Bretagne jusqu'en 1840 (pp. 86-101), où elle montre que de l'autre côté de la Manche seuls les deux derniers furent l'objet d'une forte réprobation, dans le cadre d'un débat sur le rôle et la place du gothic novel dans la fiction (le romance concurrencé par le novel).

On reprochait aux auteurs de romans gothiques leur imagination débridée et amorale, leur sensationnalisme, bref une esthétique racolleuse. À ce propos, on lira le petit mais substantiel essai d'Olivier Larizza, Charles Robert Maturin et «l'école frénétique» de Nodier (pp. 103-127), sur le frénétisme défini par Nodier en 1821 et ses liens avec l'auteur de Melmoth qu'il rattache à l'école frénétique, alors qu'une bonne part de l'œuvre du révérend échappe au genre gothique car «la composante horrifique, si essentielle au frénétisme en est absente». Gothique ou frénétique?

7 La question revient avec insistance chez la plupart des intervenants qui s'interrogent car cette appellation générique recouvre bien des éléments contradictoires. Si un contemporain comme A. Fontaney a pu voir chez Nodier une imitation médiocre des romans gothiques d'Ann Radcliffe, il arrive qu'il s'en démarque, relève Marta Sukiennicka qui rappelle les paradoxes de l'attitude de l'écrivain face à l'esthétique du roman gothique anglais, notamment dans la construction de l'espace romanesque et dans la thématique politique (Souvenirs gothiques d'Italie. "Mademoiselle de Marsan", pp. 55-68). Dans ce roman de 1832 où sont repris les codes du roman gothique, l'écriture se fait historique et mémorialiste car Nodier poursuit son projet autobiographique initié dans Souvenirs et portraits et dans les Souvenirs de jeunesse.

Georges Zaragoza voit dans l'appellation «roman gothique» un «creuset d'éléments contradictoires, voire antinomiques», d'autant plus que jusqu'en 1820, date de la parution du premier volume du grand œuvre de Taylor, Nodier et Cailleux, l'adjectif était encore marqué d'une valeur péjorative, alors que Nodier plaidait pour la reconnaissance de la valeur esthétique de l'art gothique. On visite donc l'édifice gothique selon deux séquences: Le gothique entre réalité et fiction. Le château dans "Inès de Las Sierras" et les "Voyages pittoresques" (pp. 69-86). Dans sa "petite nouvelle espagnole» de 1837, Nodier se distingue des romanciers anglais, Walpole notamment, par le recours à un chronotope exact et des références historiques précises, procédés déjà 
utilisés pour le chapitre sur l'abbaye de Jumièges dans le premier volume des Voyages pittoresques où littérature de voyage et littérature gothique se rencontrent.

9 La diffusion de la catégorie du "genre frénétique», inventée par Nodier qui d'ailleurs condamne ce genre tout en le pratiquant dans ses œuvres, commença dans les années 1860 avec la redécouverte de textes où Nodier essaie de le définir sans véritable théorisation. Il s'agit des comptes rendus du Petit Pierre de Spiess (1821), Schaueroman qui a inspiré Lewis et Byron, de Han d'slande (1823), des Albigeois, le dernier roman de Maturin (1825), et de sa préface à la traduction du Bertram de Maturin (1821). Ėmilie Pézard les présente et les commente (Ėdition des articles de Charles Nodier sur le "genre frénétique», pp. 129-162). Ce «versant noir» du romantisme, Nodier le condamne, ce qui ne l'empêche pas de le pratiquer dans Smarra. Alors que le "genre frénétique» a fait l'objet d'évaluations divergentes, grâce à ce dossier on comprend mieux le rôle de Nodier dans la conquête du romantisme, de la première définition du «frénétique» en 1821 à celle du «fantastique» en 1830 .

10 En guise de miscellanées, deux enquêtes: Bénédicte Percheron suit les transferts des connaissances entomologiques et botaniques de Nodier dans Trésor des fêves et Fleur des pois, La Fée aux miettes et Smarra (Un naturaliste contre la science? Les sciences naturelles dans l'œuvre de Charles Nodier, pp.165-183); Jacques Geoffroy, dans Trois $=$ Un (pp. 185-196), après avoir confronté les trois manuscrits du cours que Nodier donna à Dôle en 1808 et 1809 , conclut qu'ils ne sont qu'un seul et même texte, corrigeant les propos d'Annie Barraux dans son édition du Cours de belles-lettres dont plusieurs lacunes sont comblées. 